\title{
The relationship between disease severity and defense mechanisms in fibromyalgia syndrome
}

\author{
Ejder Berk ${ }^{1}$ D, Sema Baykara² (D) \\ ${ }^{1}$ Department of Physical Medicine and Rehabilitation, Kahramanmaraş Sütçü İmam University Faculty of Medicine, Kahramanmaraş, Turkey \\ ${ }^{2}$ Department of Psychiatry, Frrat University Faculty of Medicine, Elazı̆̆, Turkey
}

Received: July 04, 2018 Accepted: July 08, 2019 Published online: March 03, 2020

\begin{abstract}
Objectives: The aim of the present study was to investigate the possible relationship between the disease severity and defense mechanisms in fibromyalgia syndrome (FMS) and to contribute to the clarification of the etiopathogenesis of FMS.

Patients and methods: A total of 103 female patients (mean age: $42.6 \pm 10.0$ years; range, 20 to 67 years) diagnosed with primary FMS based on the 2016 revised American College of Rheumatology (ACR) diagnostic criteria and without any psychiatric diagnosis were included in the study. A semi-structured sociodemographic and clinical data form was used. The Fibromyalgia Impact Questionnaire (FIQ), Defense Style Questionnaire-40 (DSQ-40), Beck Depression Inventory (BDI), and Beck Anxiety Inventory (BAI) were applied to all patients. Based on the FIQ scores, the patients were divided into two groups as mild-moderate $(<70)$ and severe $(\geq 70)$ FMS groups.

Results: There were 56 patients in the mild-moderate FMS group and 47 patients in the severe FMS group. As FIQ scores increased, sublimation $(\mathrm{r}=-0.204, \mathrm{p}=0.030)$ and mature factor $(\mathrm{r}=-0.229, \mathrm{p}=0.020)$ scores decreased, and projection $(\mathrm{r}=0.210, \mathrm{p}=0.033)$ and somatization $(\mathrm{r}=0.287, \mathrm{p}=0.003)$ scores increased. Pseudoaltruism $(\mathrm{p}=0.043)$, displacement $(\mathrm{p}=0.026)$, and somatization $(\mathrm{p}=0.021)$ scores were higher in the severe FMS group. The BDI and BAI scores were also higher in the severe FMS group, compared to the mild-moderate FMS group ( $\mathrm{p}=0.001$ and $\mathrm{p}=0.002$, respectively).

Conclusion: Our study results show that there is a significant correlation between the increased disease severity, decreased mature defense mechanisms, and increased immature defense mechanisms in FMS patients.
\end{abstract}

Keywords: Defense mechanisms, fibromyalgia, severity of illness index, surveys and questionnaires.

Fibromyalgia syndrome (FMS) is a rheumatological disease, the etiology of which has not been clarified and its pathogenesis has not been fully explained, yet. The disease is characterized by symptoms such as specific sensitivity points, fatigue, insomnia, and widespread chronic pain. ${ }^{[1]}$ Core symptoms may be also accompanied by lethargy, altered sleep patterns, cognitive disorders, and sexual dysfunction that can affect daily living activities. ${ }^{[2]}$ About $2 \%$ of global population meet the 2010 American College of Rheumatology (ACR) diagnostic criteria. ${ }^{[3]}$ Fibromyalgia syndrome is three times more frequent and more clinically severe in females, compared to males. ${ }^{[4]}$ It is more frequent in individuals aged over 50 years, who live in rural areas, and with a low educational and socioeconomic level. ${ }^{[5]}$ The prognosis is poor, and recovery is rarely reported. ${ }^{[6]}$

Defense mechanisms were described by Freud as mental functions which protect the individual from intense anxiety originating from external events or from internal traumatic psychological states. ${ }^{[7]}$ The protective characteristics of ego defense mechanisms is activated to change or eliminate stressful thoughts, feelings, and perceptions. ${ }^{[7]}$

Although FMS is described as a physical disease, some authors have advocated that it is a psychological disorder and psychological factors play a role in its etiology. ${ }^{[8]}$ Despite the presence of several studies in this field in literature, there are only a few studies 
analyzing the correlation between FMS and defense mechanisms.

In the present study, we aimed to investigate the possible relationship between the disease severity and defense mechanisms in FMS and to contribute to the clarification of the etiopathogenesis of FMS where no satisfactory progress has been achieved in the treatment and prognosis.

\section{PATIENTS AND METHODS}

This single-center, cross-sectional study was conducted at Physical Medicine and Rehabilitation outpatient clinic of Kahramanmaraş Sütçü İmam University Faculty of Medicine between February 2018 and June 2018. Patients with chronic body pain, fatigue, weakness, and sleep disturbance complaints were screened and a total of 110 female patients diagnosed with primary FMS based on the 2016 revised ACR diagnostic criteria ${ }^{[9]}$ were included in the study. Clinical investigations and interviews were conducted by physical medicine and rehabilitation and psychiatry specialists. Inclusion criteria were as follows: literacy, age between 18 and 65, and no psychiatric disorders based on the Diagnostic and Statistical Manual of Mental Disorders, fourth edition (DSM-IV; Structured Clinical Interview for DSM-IV Axis 1 Disorders [SCID-I]). Exclusion criteria were as follows: the presence of concomitant rheumatological, metabolic or psychiatric disorders, diagnosis of dementia or mental retardation, and illiteracy. Accordingly, four patients were excluded from the study and further three patients who declined to participate in the study due to personal reasons were also excluded. Finally, 103 patients (103 females; mean age $42.6 \pm 10.0$ years; range, 20 to 67 years) were included in the study. All participants were asked to complete a semistructured sociodemographic and clinical data form, Fibromyalgia Impact Questionnaire (FIQ), Defense Style Questionnaire-40 (DSQ-40, Beck Depression Inventory (BDI), and Beck Anxiety Inventory (BAI). The patients were divided into two groups based on the FIQ scores as mild-moderate FMS group $(<70, \mathrm{n}=56)$ and severe $(\geq 70, \mathrm{n}=47)$ FMS group. ${ }^{[10]}$

A written informed consent form was obtained from each patient. The study protocol was approved by the Kahramanmaraş Sütçü İmam University Faculty of Medicine Ethics Committee (Date: 03.01.2018, No. 25). The study was conducted in accordance with the principles of the Declaration of Helsinki.

\section{Data collection}

A semi-structured sociodemographic and clinical data form was developed based on a literature review and within the scope of this study. The form included sociodemographic data such as age, sex, marital status, educational level, occupation, place of residence, economic status, and family structure. Clinical data including duration of the disease, number of hospitalizations, and presence of any psychosocial stress factors at the onset of the disease were also recorded.

The DSQ-40 experimentally measures conscious reflections of unconscious defense styles. The questionnaire developed by Andrews et al. ${ }^{[12]}$ is a selfreport scale which includes 40 items associated with 20 defense styles. Each item is scored between 1 and 9, where $1=$ this does not apply to me, to $9=$ this is very true in my case. A total of 20 defense mechanisms included in the scale are categorized in three groups of mature, immature, and neurotic defenses. The mature mechanisms include sublimation, humor, anticipation, and suppression. The immature defense mechanisms are projection, passive aggression, acting out, isolation, devaluation, autistic fantasy, denial, displacement, dissociation, splitting, rationalization, and somatization, and the neurotic defense mechanisms are undoing, pseudoaltruism, idealization, and reaction formation. The validity and reliability studies of the Turkish version of the scale were conducted by Yilmaz et al. ${ }^{[13]}$

The FIQ is a self-report questionnaire including 10 items which assess the conditions and outcomes of patients diagnosed with FMS. The first four-point Likert-type scale includes 10 statements. In the second and third scales, days are marked to determine the impact of the disease and inability to go to work. The scores obtained are adjusted to 10 . The remaining seven items are based on marking a visual analog scale. The scores range between 0 and 100. The FIQ was developed by Buckhardt et al. ${ }^{[14]}$ and validity and reliability studies of the Turkish version were conducted by Sarmer et al. ${ }^{[15]}$ High scores indicate a high impact. The mean is accepted as 50 and scores of $\geq 70$ are considered severe impact. ${ }^{[10]}$

The BDI was developed by Beck in 1961 to measure the depression risk in adults and to determine the levels and changes in severity of depressive symptoms. ${ }^{[16]}$ The Turkish validity and reliability studies were conducted in 1989 by Hisli. ${ }^{[17]}$ The scale cut-off point was determined as 17. It is a self-report Likert-type scale 


\begin{tabular}{|c|c|c|c|}
\hline \multicolumn{4}{|c|}{$\begin{array}{c}\text { TABLE } 1 \\
\text { The demographic characteristics of patients }\end{array}$} \\
\hline & Mild-moderate FMS $(\mathrm{n}=56)$ & Severe FMS $(\mathrm{n}=47)$ & \\
\hline & Mean \pm SD & Mean \pm SD & $p$ \\
\hline Age (years) & $42.6 \pm 9.7$ & $42.5 \pm 10.4$ & 0.939 \\
\hline Height $(\mathrm{cm})$ & $161.2 \pm 6.2$ & $161.5 \pm 6.1$ & 0.819 \\
\hline Weight (kg) & $73.4 \pm 10.0$ & $73.8 \pm 11.8$ & 0.861 \\
\hline Body mass index $\left(\mathrm{kg} / \mathrm{m}^{2}\right)$ & $28.4 \pm 4.2$ & $28.3 \pm 4.2$ & 0.926 \\
\hline
\end{tabular}

including 21 items and frequently used in studies on depression. Each item is associated with a behavioral characteristic observed in depression. The items are scored between 0 and 3 points based on the severity of depression. Total scores range between 0 and 63, where the scores between 0 and 9 indicate lack of depressive symptoms, scores between 10 and 16 indicate mild symptoms, scores between 17 and 24 indicate moderate symptoms, and scores over $\geq 25$ indicate severe symptoms.

The BAI was developed by Beck et al. ${ }^{[18]}$ It is a selfreport scale used to assess the frequency of anxiety symptoms experienced by an individual. It includes 21 items scored between 0 and 3 on a Likert-type scale. Validity and reliability tests of the Turkish version of the scale were conducted by Ulusoy. ${ }^{[19]}$

\section{Statistical analysis}

Statistical analysis was performed using the IBM SPSS version 22.0 software (IBM Corp., Armonk, NY, USA). Descriptive data were expressed in mean \pm standard deviation (SD), median (min-max) or number and frequency. Conformity of the data to normal distribution was analyzed with the Kolmogorov-Smirnov test. Analysis of two independent groups was conducted using the Student's t-test. The Pearson correlation analysis was used to examine the correlations between the groups, and $p$ values of $<0.05$ and $<0.01$ indicate a poor and strong correlation, respectively. A $p$ value of $<0.05$ was considered statistically significant.

\section{RESULTS}

In this study, a total of 103 patients with FMS were evaluated. There was no significant difference in the age, height, weight, and body mass index between the mildmoderate FMS and severe FMS groups. Demographic characteristics of the patients are shown in Table 1.

The BDI and the BAI scores were significantly higher in the severe FMS group, compared to the mild-moderate FMS group ( $\mathrm{p}<0.001$ and $\mathrm{p}=0.002$, respectively) (Table 2).

There was a weak, negative correlation between the FMS severity and sublimation $(r=-0.204, p=0.030)$ and FMS severity and mature factor scores $(r=-0.229$, $\mathrm{p}=0.020$ ). Also, there was a weak, but positive correlation between the FMS severity and projection $(\mathrm{r}=0.210$, $\mathrm{p}=0.033)$ and FMS severity and somatization scores $(\mathrm{r}=0.287, \mathrm{p}=0.003)$.

In addition, pseudoaltruism ( $\mathrm{p}=0.043)$, displacement $(\mathrm{p}=0.026)$, and somatization $(\mathrm{p}=0.021)$ scores were statistically significantly higher in the severe FMS group, compared to the mild-moderate FMS group. However, no significant difference was found in the other parameters between the groups (Table 3).

\begin{tabular}{|c|c|c|c|}
\hline \multicolumn{4}{|c|}{$\begin{array}{l}\text { TABLE } 2 \\
\text { Association of fibromyalgia symptom severity with depression and anxiety }\end{array}$} \\
\hline & Mild-moderate FMS $(\mathrm{n}=56)$ & Severe FMS $(\mathrm{n}=47)$ & \\
\hline & Mean \pm SD & Mean \pm SD & $p$ \\
\hline Fibromyalgia impact questionnaire & $55.6 \pm 12.0$ & $78.8 \pm 5.8$ & $<0.001$ \\
\hline Beck depression inventory & $17.2 \pm 7.0$ & $23.8 \pm 8.9$ & $<0.001$ \\
\hline Beck anxiety inventory & $23.5 \pm 10.3$ & $30.9 \pm 13.5$ & $<0.002$ \\
\hline
\end{tabular}




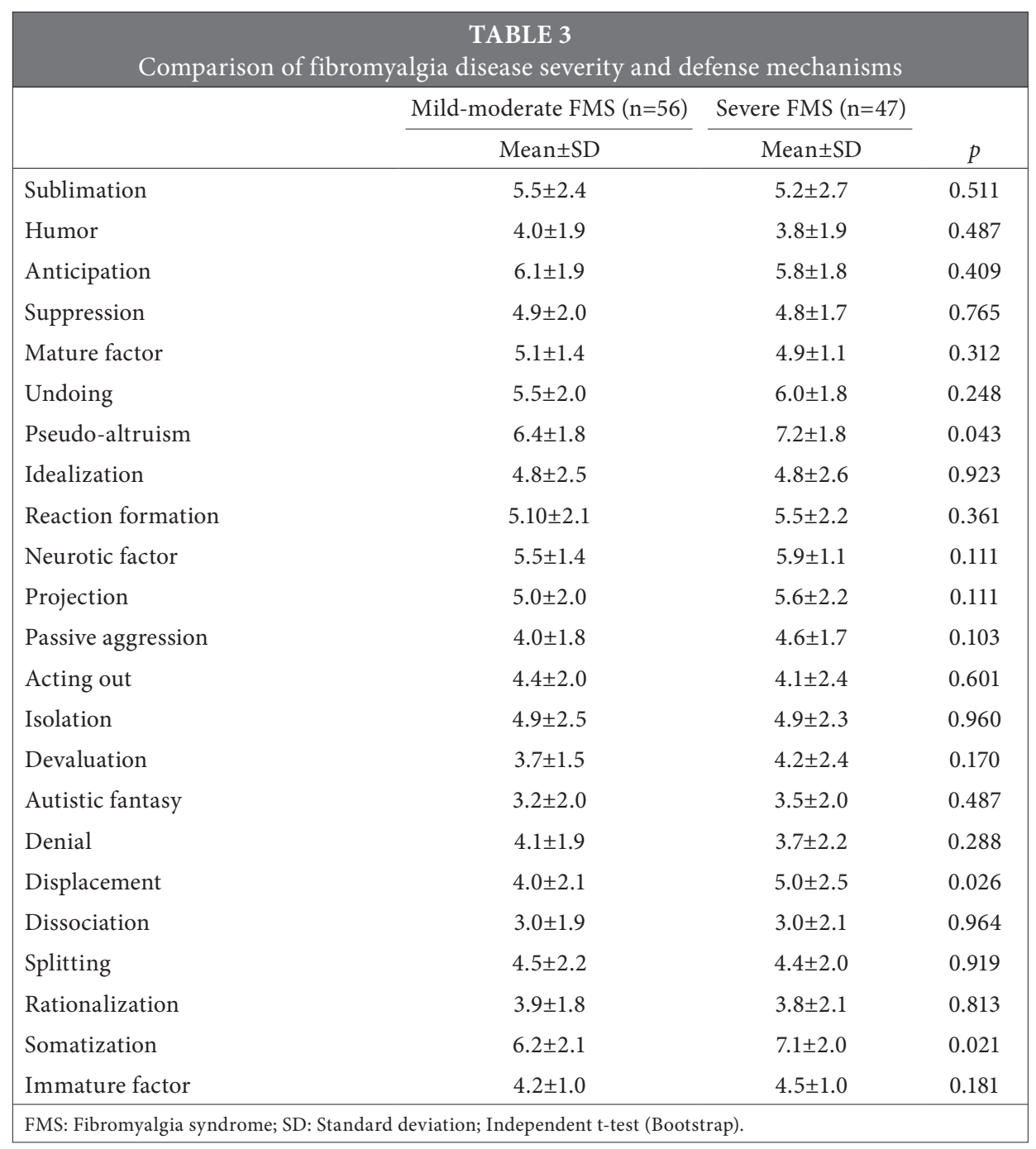

\section{DISCUSSION}

Analysis of the sociodemographic characteristics of the patients included in the current study demonstrated that these parameters are consistent with the demographics of this patient population as reported in the literature, where the majority of patients were middle-aged females. Although FMS has been shown to be more frequent in patients with a low socioeconomic level, the socioeconomic levels of the current study patients were mostly middle-income. This discrepancy can be explained by the fact that the educational level of the patients in the current study was not quite low and, thus, their income levels were higher, compared to previous reports in the literature. ${ }^{[20,21]}$

Fibromyalgia syndrome, frequently accompanied by a psychiatric diagnosis, is a syndrome which requires a detailed clinical examination to achieve success in treatment. ${ }^{[22]}$ Diseases with chronic pain symptoms such as FMS, rheumatoid arthritis (RA), irritable bowel syndrome (IBS), and migraine are known to be associated with high rates of comorbidities such as anxiety and depression. ${ }^{[23]}$ A correlation was reported between mood and severe pain in FMS patients and negative thoughts about physical health were shown to be nurtured by the predominant mood in these patients. ${ }^{[2]}$ In the current study, FMS was correlated with anxiety and depression and, as the FIQ scores increased, the BAI and BDI scores increased as well, consistent with previous findings in the literature. ${ }^{[22,24]}$

In previous studies examining the correlation between FMS and anxiety and depression, the level of pain perceived by patients with FMS and severe 
anxiety and depression was higher, compared to those with mild and moderate anxiety and mild depression, and there was a clear correlation between anxiety and depression scores and the severity of the disease. In addition, females with a high level of depression and anxiety experienced high perceptions of pain and were at high risk for FMS. ${ }^{[8]}$

The view that pain, and particularly chronic pain, may be associated with ego defense mechanisms has long been a focus of interest in the field of psychiatry. However, there are few studies in the literature investigating the correlation between defense mechanisms and diseases with chronic pain..$^{[25-28]}$ Tauschke et al. ${ }^{[25]}$ compared a patient group with chronic pain and a patient group with a childhood history of psychiatric diagnosis and no complaints of pain to analyze the correlation between depression and defense mechanisms. The authors found no significant difference between the defense mechanisms adopted by chronic pain patients and general population using mature defense mechanisms more, compared to those with a psychiatric diagnosis. Even when there were few concomitant psychiatric symptoms, anxiety and depression scores were found to be high.

In the current study, the adopted defense mechanisms were compared by dividing the FMS patients into two groups based on their FIQ scores: mild-moderate FMS $(<70)$ and severe $(\geq 70)$ FMS. Thus, we observed that the mature factor and sublimation (mature defense mechanisms) subscale scores decreased and projection and somatization (immature defense mechanisms) subscale scores increased, as the FIQ scores increased. In other words, as the severity of the disease increased, the use of mature defense mechanisms decreased and the use of immature defense mechanisms increased, and as the disease severity decreased, the use of mature defense mechanisms increased. These findings are also consistent with the reports by Tauschke et al. ${ }^{[25]}$ suggesting that the defense mechanisms used by patients with chronic pain did not differ significantly with those experienced by the general population. Therefore, the replacement of mature defense mechanisms by immature defense mechanisms was not defined by the disease itself, but rather by the severity of the disease. This finding is supported by the data reported in the literature that those who utilized displacement, somatization, and passive-aggression mechanisms more experienced severe somatic symptoms. ${ }^{[29]}$

Furthermore, we observed that the pseudoaltruism, displacement, and somatization subscale scores were higher in severe FMS patients, compared to patients with mild-moderate FMS. Pseudoaltruism was accepted as feeling good about self-perception, helping others, and remaining calm. Along with refusal to be hostile to others, communications may be impaired, leading to neglect of one's own needs. ${ }^{[21]}$ In addition, those with a chronic disease who were more concerned with the problems of others neglected self-care. ${ }^{[30]}$ Displacement is the transformation of emotions, thoughts, desires, and urges to more acceptable, but less important ones. Thus, by escaping from a real unacceptable situation which may lead to problems, individuals transform the situation into another situation that may cause less concern.

In earlier studies, patients diagnosed with FMS were identified as perfectionist, driven individuals with expectations from those around them, who experience difficulties in expressing their emotions verbally, and have irritable personalities. ${ }^{[31]}$ Desires and impulses which would not be acceptable under normal conditions may be replaced by physical symptoms that are subconsciously more acceptable in this group of patients. Thus, they would avoid conflict with other individuals and could adopt a more harmonious approach to the outside world.

Somatization is a defense mechanism used to eliminate anxiety of an unknown etiology by associating the anxiety with a concrete source, cause, or situation. Problems and tensions engender physical symptoms in an individual and, rather than mental symptoms, different complaints are observed in different localizations in the body. ${ }^{[32]}$ Previous studies demonstrated that somatization was a primary defense mechanism in patients with chronic pain. ${ }^{[33]}$ Brosschot and Aarsse ${ }^{[34]}$ reported that FMS patients experienced alexithymia more than healthy controls and experienced difficulties in expressing emotions and thoughts verbally. By reflecting internal experiences in the form of physical symptoms, these patients develop a method of dealing with subconscious anxiety. However, there are conflicting results in studies examining the correlation between defense mechanisms and states of chronic pain. In a study comparing IBS patients and a healthy control group based on defense mechanisms, no significant difference was found between the groups, and the effect of the defense mechanisms was a permanent personality trait and was not associated with functional colon impairment in IBS patients. ${ }^{[26]}$ In another study, defense mechanisms were compared between an 
untreated chronic migraine patient group and a healthy control group using the Defense Mechanism Inventory, and suppression and self-harm (neurotic defense mechanisms) subscale scores were higher. ${ }^{[27]} \mathrm{A}$ positive correlation was found between the frequency of pain and suppression and self-harm in migraine patients. Additionally, Leavitt et al. ${ }^{[35]}$ reported that the dissociation defense mechanism was used by FMS patients more than RA patients. Landmark et al. ${ }^{[28]}$ also showed that FMS was not associated with overuse of defense mechanisms; however, there was a correlation between the use of these mechanisms and an accompanying psychopathology. In the current study, the decrease in the use of mature defense mechanisms and the increase in the use of immature defense mechanisms was associated with the increase in disease severity. In FMS treatment, consideration of psychotherapeutic approaches that would increase the use of mature defense mechanisms would contribute to the prognosis of the disease.

Nonetheless, there are some limitations to the present study. It is not possible to completely dismiss the use of medication in diseases with chronic pain such as FMS. However, the use of defense mechanisms was found to be associated with disease severity. Future studies including patients who do not take any medication would reveal more accurate results. Although FMS is observed more frequently in females, it is seen in both sexes; thus, the limitation of the current study group to only female patients prevented generalization of the results. In addition, this was a cross-sectional study. Further prospective studies investigating chronic diseases could provide more detailed information about the etiopathology of the disease. Finally, the exclusion of mild cases and control subjects and division of the patients into two groups as mild-moderate and severe to compare the severity of FMS and the defense mechanism subgroups can be considered another limitation. Comprehensive analysis of control subjects with mild, moderate, and severe FMS cases would provide further valuable information in future studies.

In conclusion, FMS is not solely a rheumatological disease or a mental disorder, but a cluster of symptoms that include a combination of symptoms in these fields. To the best of our knowledge, there are only few studies investigating defense mechanisms in FMS and none of these included an analysis of the correlation between these mechanisms and disease severity. Therefore, our study is valuable, since this is the first study to demonstrate that the use of mature defense mechanisms can be decreased and the use of immature defense mechanisms can be increased with elevated disease severity in FMS patients. This study also indicates that interdisciplinary approach is important not only in the management, but also in the enlightenment of the etiopathogenesis of FMS. Nevertheless, further prospective studies with larger sample sizes including both sexes are required to establish a more accurate results and to provide a greater contribution to the literature.

\section{Declaration of conflicting interests}

The authors declared no conflicts of interest with respect to the authorship and/or publication of this article.

\section{Funding}

The authors received no financial support for the research and/or authorship of this article.

\section{REFERENCES}

1. Wolfe F, Smythe HA, Yunus MB, Bennett RM, Bombardier C, Goldenberg DL, et al. The American College of Rheumatology 1990 Criteria for the Classification of Fibromyalgia. Report of the Multicenter Criteria Committee. Arthritis Rheum 1990;33:160-72.

2. Bertolucci PH, de Oliveira FF. Cognitive impairment in fibromyalgia. Curr Pain Headache Rep 2013;17:344.

3. Wolfe F, Brähler E, Hinz A, Häuser W. Fibromyalgia prevalence, somatic symptom reporting, and the dimensionality of polysymptomatic distress: results from a survey of the general population. Arthritis Care Res 2013;65:777-85.

4. Macfarlane GJ, Kronisch C, Dean LE, Atzeni F, Häuser W, Fluß E, et al. EULAR revised recommendations for the management of fibromyalgia. Ann Rheum Dis 2017;76:318-28.

5. Queiroz LP. Worldwide epidemiology of fibromyalgia. Curr Pain Headache Rep 2013;17:356.

6. Richards S, Cleare AJ. Fibromyalgia: biological correlates. Curr Opin Psychiatry 2000;13:623-8.

7. Freud A. The Ego and the Mechanisms of Defense. New York; International Universities Press; 1946.

8. Aparicio VA, Ortega FB, Carbonell-Baeza A, Cuevas-Toro AM, Delgado-Fernández M, Jonatan R. Anxiety, depression and fibromyalgia pain and severity. Psicología Conductual 2013;21:381.

9. Wolfe F, Clauw DJ, Fitzcharles MA, Goldenberg DL, Häuser W, Katz RL, et al. 2016 Revisions to the 2010/2011 fibromyalgia diagnostic criteria. Semin Arthritis Rheum 2016;46:319-29.

10. Bennett R. The Fibromyalgia Impact Questionnaire (FIQ): a review of its development, current version, operating characteristics and uses. Clin Exp Rheumatol 2005;23:S154-62.

11. Riis P. Perspectives on the Fifth Revision of the Declaration of Helsinki. JAMA 2000;284:3045-6. 
12. Andrews G, Singh M, Bond $M$. The defense style questionnaire. J Nerv Ment Dis 1993;181:246-56.

13. Yilmaz N, Gençöz T, Ak M. Psychometric properties of the defense style questionnaire: a reliability and validity study. Turk Psikiyatri Derg 2007;18:244-53.

14. Burckhardt CS, Clark SR, Bennett RM. The fibromyalgia impact questionnaire: development and validation. J Rheumatol 1991;18:728-33.

15. Sarmer S, Ergin S, Yavuzer G. The validity and reliability of the Turkish version of the Fibromyalgia Impact Questionnaire. Rheumatol Int 2000;20:9-12.

16. Beck AT, Ward CH, Mendelson M, Mock J, Erbaugh J. An inventory for measuring depression. Arch Gen Psychiatry 1961;4:561-71.

17. Hisli N. Effect of patients' evaluation of group behavior on therapy outcome. Int J Group Psychother 1987;37:119-24.

18. Beck AT, Epstein N, Brown G, Steer RA. An inventory for measuring clinical anxiety: psychometric properties. J Consult Clin Psychol 1988;56:893-7.

19. Ulusoy M, Sahin NH, Erkmen H. Turkish Version of the Beck Anxiety Inventory: Psychometric Properties. J Cogn Psychother 1998;12:2.

20. Wolfe F, Ross K, Anderson J, Russell IJ, Hebert L. The prevalence and characteristics of fibromyalgia in the general population. Arthritis Rheum 1995;38:19-28.

21. Sayar K, Acar B, Aydın T. Fibromiyalji hastalarında umutsuzluk ve depresyon. Nöropsikiyatri Arşivi 1999;36:27-32.

22. Silverman SL, Harnett J, Zlateva G, Mardekian J. Identifying fibromyalgia-associated symptoms and conditions from a clinical perspective: a step toward evaluating healthcare resource utilization in fibromyalgia. Pain Pract 2010;10:520-9.

23. Bennett RM, Jones J, Turk DC, Russell IJ, Matallana L. An internet survey of 2,596 people with fibromyalgia. BMC Musculoskelet Disord 2007;8:27.

24. Jensen KB, Petzke F, Carville S, Fransson P, Marcus H, Williams SC, et al. Anxiety and depressive symptoms in fibromyalgia are related to poor perception of health but not to pain sensitivity or cerebral processing of pain. Arthritis Rheum 2010;62:3488-95.

25. Tauschke E, Merskey H, Helmes E. Psychological defence mechanisms in patients with pain. Pain 1990;40:161-70.

26. Zoccali R, Muscatello MR, Bruno A, Barillà G, Campolo $\mathrm{D}$, Meduri M, et al. Anger and ego-defence mechanisms in non-psychiatric patients with irritable bowel syndrome. Dig Liver Dis 2006;38:195-200.

27. Passchier J, Goudswaard P, Orlebeke JF, Verhage F. Migraine and defense mechanisms: psychophysiological relationships in young females. Soc Sci Med 1988;26:343-50.

28. Landmark T, Stiles TC, Fors EA, Holen A, Borchgrevink PC. Defense mechanisms in patients with fibromyalgia and major depressive disorder. Eur J Psychiat 2008;22:185-93.

29. Hyphantis TN, Taunay TC, Macedo DS, Soeiro-deSouza MG, Bisol LW, Fountoulakis KN, et al. Affective temperaments and ego defense mechanisms associated with somatic symptom severity in a large sample. J Affect Disord 2013;150:481-9.

30. Lane JD, McCaskill CC, Williams PG, Parekh PI, Feinglos MN, Surwit RS. Personality correlates of glycemic control in type 2 diabetes. Diabetes Care 2000;23:1321-5.

31. Smythe H. Fibrositis and other diffuse musculoskeletal syndromes. In: Kelley WN, Harris ED, Ruddy S, Sledge CB, editors. Textbook of Rheumatology. Philadelphia: Saunders; 1981. p. 485-93.

32. Öztürk MO, Uluşahin A. Ruh sağlığı ve bozuklukları. İstanbul: Nobel Tip Kitabevleri; 2011.

33. Monsen K, Havik OE. Psychological functioning and bodily conditions in patients with pain disorder associated with psychological factors. Br J Med Psychol 2001;74:183-95.

34. Brosschot JF, Aarsse HR. Restricted emotional processing and somatic attribution in fibromyalgia. Int J Psychiatry Med 2001;31:127-46.

35. Leavitt F, Katz RS, Mills M, Heard AR. Cognitive and dissociative manifestations in fibromyalgia. J Clin Rheumatol 2002;8:77-84. 